\title{
A new proposal for collection and generation of information on financial institutions' risk: The case of derivatives
}

\author{
Gilneu F. A. Vivan and Benjamin M. Tabak* \\ ${ }^{*}$ Banco Central do Brasil, Research Department, SBS Quadra 3, Bloco B. Ed. Sede, \\ 9 andar, Brasilia DF 70074-900, Brazil. \\ Tel: + 5561 34142045, Fax: + 5561 34142045, E-mail: Benjamin.tabak@bcb.gov.br
}

Received (in revised form): 15th February, 2007

Gilneu F. A. Vivan is Head of the Off-Site Department of Banco Central do Brasil, holds an MSc in Economics and is a specialist in the analysis of banking system risk.

Benjamin M. Tabak is Senior Advisor of the Research Department of Banco Central do Brasil, holds a PhD in Economics from Universidade de Brasilia and has published papers in portfolio and risk management areas in a variety of financial and economics journals.

\section{Practical applications}

The following sections contain reports that reproduce the proposed information sets for linear and nonlinear instruments. The comments on the use of each one and the results of some tests are also presented.

\begin{abstract}
This paper aims at providing a new alternative for the collection of information on risks taken by financial institutions, which enables the calculation of risk tools usually used in risk management, such as VaR and stress tests. This approach should help risk managers, off-site supervisors and academics in assessing the potential risks in financial institutions principally due to derivatives positions. The basic idea, for linear financial instruments, like that traditionally used by the management risk systems, is to reduce positions in risk factors and then map the vertices. For the nonlinear financial instruments, all the positions in different types of options - European, American, exotic, etc - are

represented as plain vanilla European options or

replicated by portfolios of plain vanilla European options.

The methodology was applied to Brazil, within the

worst scenarios during the period from 1994 to 2004,
\end{abstract}

Journal of Derivatives \& Hedge Funds, Vol. 13 No. 2, 2007 , pp. 147-169 (C) 2007 Palgrave Macmillan Ltd $1753-9641 \$ 30.00$ and the paper demonstrates that the proposed approach captured the risks satisfactorily in the analysed portfolios, including the risk existent in the strategies involving options, given an accepted error margin. This approach could be useful for regulators, risk managers, financial institutions and risk management modelling as it can be used as an input in general risk management models. Journal of Derivatives \& Hedge Funds (2007) 13, 147-169. doi:10.1057/palgrave.jdhf.1850061

Keywords: derivatives; information; risk management; off-site supervision; systemic risk

'The end result is that a major component of bank profitability over the last decade does not appear in any consistent way in the financial reports of banks. Shareholders and financial analysts find it difficult to assess bank performance, while regulators and rating 
agencies face problems when they try to determine the riskiness of bank activities. Likewise the true risk profile of some nonblank corporation may also be unclear from their financial reports.' (Crouhy et al.) ${ }^{1}$

\section{INTRODUCTION}

The analysis of accounting and non-accounting information provided by financial institutions to the supervisory bodies is one of the main tools to evaluate a financial institution's risk. Furthermore, another tool is the comparison of this information with the information regarding other financial institutions with the same profile. These tools are often used by supervisors throughout the world for the monitoring and identification of institutions, which could present problems or become a source of concern, requiring the adoption of preventive actions.

This information is generally summarised through indicators by the supervisory body. Indicators are relations among groups of information of each institution, which make information comparable. One of the most wellknown examples of a group of indicators is the Uniform Bank Performance Report - UBPR, created by the Federal Deposit Insurance Corporation - FDIC of the Federal Financial Institutions Examination Council - FFIEC from the United States of America.

When the reality is summarised in a document or report, some information is always lost. Nevertheless, the classical structure of accounting and disclosure positions held by financial institutions and indicators present satisfactory outcomes insofar as the main income source is financial intermediation. If not, this assertion is not true.

The increasing demand for derivatives and the evolution of risk management techniques dramatically changed the profile of some institutions to the point that revenues from the intermediation of 'risks' have become the major source of revenue. Moreover, the effects of derivatives on the equity structure are not properly reflected in the financial statements.

The difficulty in understanding the information and risks involved in derivatives positions is of concern to regulators because (i) the adequate treatment of information on derivatives is essential to the supervisors' information collection regarding the financial health of institutions and (ii) financial analysts have difficulties in assessing institutions without comprehensive information regarding the risks inherent to the derivatives operations held by those institutions. ${ }^{2}$

With the purpose of addressing this problem, important international efforts towards the assessment of the risk involved in positions held by financial institutions and its disclosure to the interested public have been made by the Financial Accounting Standard Board (FASB), ${ }^{3-7}$ by the Bank of International Settlements (BIS) ${ }^{8-11}$ and by the International Organization of Securities Commissions (IOSCO). ${ }^{12}$

Nonetheless, it is up to the supervisory authority to monitor the economic and financial situation of banks. ${ }^{13,14}$ In order to perform this duty, the information collection, which makes viable the understanding of each bank's risk exposure, is essential.

While reviewing the information collected by some supervisory entities, ${ }^{15}$ it is noticed that the data essentially aims at monitoring the capital requirements for the regulated risks. In their majority, they are accounting for data that enable the identification of the share of each financial instrument, but not the risk associated to them.

Even when the risk associated to an instrument is calculated in a more elaborate manner - options, for example - the 
presentation form aims exclusively at calculating the Basle capital requirements, and therefore does not enable a more profound study. Nevertheless, there is other complimentary information required by supervisory authorities that can help in risk estimation. Luxembourg, for example, requires a document in which assets and liabilities are presented according to maturity bands, but the risk factors are not identified.

Yet regarding this issue, it is important to remember one BIS statement, in the 'Recommendations for public disclosure of trading and derivatives activities': the information should be comparable, because the comparability enables users to assess the financial position and performance of institutions compared to other institutions. Moreover, comparability over time is necessary for the identification of trends. ${ }^{16-18}$

The simple collection of numbers generated by financial institutions in their management risk systems, for example, would not fulfil this requirement, because these numbers are not comparable, as each institution calculates its risk using standards of measure considered to be more appropriate, defined, according to its own criteria, be it through the calculation method (parametric, historical simulation, etc), the parameters of holding period and level of confidence, the criteria for risk aggregation and the yield curve among others.

Another way to collect data would be the prior definition, by the supervisory authority, of the VaR calculation methodology or of the stress scenarios to be applied. This would, as a consequence, bring the discouragement of evolution of more powerful risk calculation methodologies, and could induce the supervisor to commit mistakes, because, according to the combination of an institution's positions, the stress scenario shall not be an extreme fluctuation in the market prices, but, instead, a small oscillation. ${ }^{19,20}$
The need for obtaining the same risk measure for all institutions, using the same methodology, at the same date, and the possibility of using different scenarios, defined by supervisors, for all institutions at the same time, on a comparable basis, which integrate, even on a primitive way, the market risk and the credit risk, is a challenge to supervisors, because of the potential that such information could aggregate to the supervisory activity. Moreover, this would enable the development of new comparable indicators, to be disclosed or not, as, for example, VaR by equity or loss in the worst scenario for the institution by its equity.

It must be clear that it is not up to the supervisory authority to manage supervised banks' risks, but only understand the risk profile of each institution and monitor the risk volume of each one according to its equity, for example. Therefore, the proposed system should present an error margin in the results that enables knowing the institution, detecting eventual problems, even though not being precise.

This paper aims at assessing some alternatives of collection of information on risks taken by financial institutions, which enable the supervisor to calculate the risk averages usually used in risk management, like VaR and stress tests, for example, using for all institutions the same methodology and comparing the results among institutions over time, not having to face those limitations.

The objective is to define a set of information sufficient for the proposed calculation, based on information used in most popular risk systems (as, RiskMetrics ${ }^{\mathrm{TM} 21}$ for example), not giving rise to more expenses for institutions, which could discourage the development of safer practices of risk management, or interfering in the management process of each institution.

In this paper, these sets of information are approached only under a stress test view, because, 
if they are adequate for this kind of analysis, they are also adequate for other risk measures calculations, as VaR, for example, using the same Monte Carlo simulation techniques or historical simulation, which basically consist in the distribution analysis resulting in the application of various scenarios on the existing positions.

As noticed before, when positions held by an institution are summarised on a report, some information is lost. Therefore, when applied to a stress scenario, for instance, the result obtained by institutions using all the available information (full valuation) would be more precise than the one obtained by using only the reports where those positions are summarised.

Therefore, the first question is to establish the acceptable error on those methodologies. The parameter to be used in this paper is the same as that obtained on a survey responded to by 47 risk management professionals, where the conclusion was that they would accept the use of risk measures obtained based on reports, provided the difference between this result and the results obtained through full valuation was less than \pm 10 per cent.

According to the objective of using the financial instrument as the basis for the definition of the set of information to be collected by the management risk system, the financial instruments were classified as linear or nonlinear instruments. This classification describes the relation between a financial instrument's face value and its risk factors. Generally speaking, it is classified as a linear financial instrument in which a fluctuation on its risk factors causes the same effect over the value of the financial instrument. ${ }^{22}$

In practice, generally speaking, there is a linear relation and a nonlinear relation among risk factors and the price of a financial instrument.
The latter relation can or cannot be ignored, according to its relevance to the formation of the financial instrument's value and the relevance of this instrument to the portfolio.

The following financial instruments are considered linear: securities, shares, foreign currencies, commodities and some derivatives such as swaps and futures, which do not present options, or characteristics which pose limits or nullify their payoffs as, for instance, cap, floor, etc. Options and contract characteristics in financial instruments, which work as options, generally denominated embedded options, are considered nonlinear. Throughout the bibliography used, financial instruments classified as linear and nonlinear are the same.

In comparisons performed throughout this paper, among values obtained by full valuation and those obtained using the proposed set of information, in different scenarios, the error generated according to the following equation defines if a comparison is acceptable or not:

$$
\text { error }=\frac{V_{F V}-V_{C I}}{V_{F V}}
$$

where $V_{F V}$ is the value obtained by full valuation and $V_{C I}$ is the value obtained using the set of information.

To create these scenarios, the variations in all the cases were more severe than those that happened in the last ten years in Brazil, when the crises in Russia, Asia, Brazil and Argentina occurred.

In this paper, the focus was on bank supervision, but this approach could be useful for others like risk managers, financial institutions or academicians. Risk managers could use these data as an input in general risk management models. 
The paper is divided as follows. In the next section, we show how to evaluate risk for linear financial instruments, while the subsequent section focuses on non-linear financial instruments. The penultimate section presents the proposed information set that can be helpful in assessing a financial institution's risk due to exposure to derivatives, while the final section concludes the paper.

\section{LINEAR FINANCIAL INSTRUMENTS}

The risk management systems, RiskMetrics ${ }^{\mathrm{TM}}$, for instance, total all positions in linear instruments marked-to-market, according to the risk factor, instead of financial instrument. In the second stage, after totalling up the risk factor, the maturities are mapped into standardised position vertices, and then the risk calculations are performed. These procedures significantly reduce the volume of data to be processed through the system.

The first test to be performed aims at verifying if the positions in financial instruments classified by risk factors and vertices, enable the use of stress tests considered to be adequate by the supervisor. The results are within the range of \pm 10 per cent of difference among the number that would have been obtained by full valuation and are obtained based on the information set.

The test was performed in a foreign currency security with credit risk $\mathrm{BBB},{ }^{23}$ and maturing in one year. Theoretically, the future value of this security is given by the following equation:

$$
V F=M \times S \times(1+d)
$$

where $V F$ is the future value of the security; $A$ is the amount of foreign currency to be paid at maturity date (including the interest); $S$ is the spot rate of the foreign currency and $d$ is the foreign exchange change estimated for the period.
The present value is:

$$
V P=\frac{V F}{\left(1+i_{c}\right)}
$$

where $V P$ is the present value of the security; $i_{c}$ is the discount rate, considering the credit risk of the issuer. In this paper, $i_{c}$ is defined ${ }^{24}$ as $i_{c}=(1+r)(1+r c)$, where $r$ is the rate free of risk and $r$ is the credit risk of the issuer.

Replacing equation (1) in equation (2) and considering the definition of $i_{c}$ :

$$
V P=\frac{A \times S \times(1+d)}{(1+r)(1+r c)}
$$

where $r$ is the risk-free interest rate and $r$ is the credit risk of the issuer.

In Brazil, there is no significant market of foreign exchange fluctuation. Therefore, the foreign exchange coupon market (cc) is used, which relates the domestic interest rates with the foreign exchange fluctuation, that is, it represents the domestic interest rate in American dollars, in order to establish the present value of the security.

Replacing equation (4) in equation (3):

$$
\begin{gathered}
(1+c c)=\frac{(1+r)}{(1+d)} \\
V P=\frac{A \times S}{(1+c c)(1+r c)}
\end{gathered}
$$

Equation (5) defines the present value of the security. The risk factors of a financial instrument, generally speaking, are the parameters that influence the calculation of a present value of a financial instrument. In this case, the risk factors are $f(S, c c, r c)$. The next step is to identify the relation between these risk factors and the security value. The fluctuation of the present value of the security $(V P)$, in relation to the present value when the parameters are changed according to the scenario $\alpha\left(S^{\alpha}, c c^{\alpha}, r c^{\alpha}\right)$, 
is given by:

$$
\frac{V P^{\alpha}}{V P}-1=\ln \left(\frac{V P^{\alpha}}{V P}\right)
$$

Replacing $V P$ and $V P^{\alpha}$ in the second part of equation (6) by equation (5) and simplifying:

$$
\begin{aligned}
\ln \left(\frac{V P^{\alpha}}{V P}\right)= & \ln \left(\frac{S^{\alpha}}{S}\right)-\ln \left(\frac{1+c c^{\alpha}}{1+c c}\right) \\
& -\ln \left(\frac{1+r_{B B B}^{\alpha}}{1+r c_{B B B}}\right)
\end{aligned}
$$

Therefore, one long position on a foreign exchange security with credit risk $\mathrm{BBB}$ is separated into the following risk factors: ${ }^{20,25}$ one long position on foreign currency; one short position in foreign exchange coupon and one short position on credit risk BBB. In order to calculate the value of the security using linear estimation, the following equation is used:

$$
\begin{aligned}
V P_{F R}^{\alpha}= & \frac{\left(S^{\alpha}-S^{0}\right)}{S^{0}} V P^{0}-\frac{\left(c c^{\alpha}-c c^{0}\right)}{\left(1+c c^{0}\right)} V P^{0} \\
& -\frac{\left(r c_{B B B}^{\alpha}-r c_{B B B}^{0}\right)}{\left(1+r c_{B B B}^{0}\right)} V P^{0}+V P^{0}
\end{aligned}
$$

where $V P_{F R}^{\alpha}$ is the present value of the security estimated using the risk factors of the $\alpha$ scenario; 0 is the value of the parameters and of the securities at the initial scenario.

Using equation (5) and assuming as initial parameters: $S^{0}=3, r^{0}=15$ per cent and $c^{0}=5$ per cent and $r c_{B B B}^{0}=0.1796$ per cent, the present value of this security in the initial scenario is 2.8520 .

The value of $r_{B B B}^{0}$ is calculated based on the table presented by Crouhy et al., ${ }^{1}$ which present the following default rates calculated by Standard \& Poor's, based on the following relation between credit risk and default probability: ${ }^{26}$

$$
(1+r)=\frac{1}{(1-p)}
$$

where $p$ is the default probability (Table 1 ).

Two scenarios were applied to this security: spot value of foreign currency unit ranging between 1 and 5 Reais, with 25 cent intervals; foreign exchange coupon ranging from 2 to 20 per cent, in intervals of 0.5 per cent. For the credit risk, it was considered the increase and the decrease of credit quality in 1 or 2 levels, using the probabilities given by Standard \& Poor's table. Considering all possible combinations of these scenarios, 1,530 scenarios were tested.

It is important to note that, in the process of building this scenario, there was no concern with the economical reasonability. Simply, it aims at evaluating if, when using different stress scenarios, disregarding the consistency of the used scenario, the results obtained by full valuation (equation 5) are equivalent to those obtained using the risk factors (equation 8).

Even using these scenarios with fluctuations much higher than the stress scenarios normally used, the outcomes obtained show that in 87.8 per cent of the generated scenarios, the fluctuation remained within the proposed error margin. Even considering only the combinations of extreme fluctuations of each risk factor, 74.1 per cent remained within the acceptable margin (Table 2).

In another test performed with a foreign currency future, applying the same methodology and the same scenarios, with the exception of the credit risk, and including the scenarios for the risk-free interest rate, beginning at 15 per cent and ranging between 5 and 29 per cent, in intervals of 2 points, totalling 3,978 scenarios, the error using linear estimation by risk factors instead of the theoretical value equation, in 96.5 
Table 1: Aggregated default rate

\begin{tabular}{|c|c|c|c|c|c|c|c|c|}
\hline Rating & 1 & 2 & 3 & 4 & 5 & 7 & 10 & 15 \\
\hline AAA & - & - & 0.07 & 0.15 & 0.24 & 0.66 & 1.40 & 1.40 \\
\hline $\mathrm{AA}$ & - & 0.02 & 0.12 & 0.25 & 0.43 & 0.89 & 1.29 & 1.48 \\
\hline A & 0.06 & 0.16 & 0.27 & 0.44 & 0.67 & 1.12 & 2.17 & 3.00 \\
\hline $\mathrm{BBB}$ & 0.18 & 0.44 & 0.72 & 1.25 & 1.78 & 2.99 & 4.34 & 4.70 \\
\hline BB & 1.06 & 3.48 & 6.12 & 8.68 & 10.97 & 14.46 & 17.73 & 19.91 \\
\hline B & 5.20 & 11.00 & 15.95 & 19.40 & 21.88 & 25.14 & 29.02 & 30.65 \\
\hline CCC & 19.79 & 26.92 & 31.63 & 35.97 & 40.15 & 42.64 & 45.10 & 45.10 \\
\hline
\end{tabular}

Source: Standard \& Poor's (15th April, 1996).

Crouhy et al. ${ }^{1}$

Table 2: Error in a linear asset with credit risk

\begin{tabular}{lcccccc}
\hline Gap bands & $\begin{array}{c}\text { Extreme } \\
\text { scenarios }\end{array}$ & \% vertical & $\begin{array}{c}\text { Other } \\
\text { scenarios }\end{array}$ & \% vertical & All scenarios & \% vertical \\
\hline Between -30 and $-10 \%$ & 4 & 14.8 & 159 & 10.6 & 163 & 10.7 \\
Between -10 and -5\% & 5 & 18.5 & 144 & 9.6 & 149 & 9.7 \\
Between -5 and -2.5\% & 3 & 11.1 & 76 & 5.1 & 79 & 5.2 \\
Between -2.5 and 0\% & 2 & 7.4 & 526 & 35.0 & 528 & 34.5 \\
Between 0 and 2.5\% & 10 & 37.0 & 474 & 31.5 & 484 & 31.6 \\
Between 2.5 and 5\% & & 0.0 & 63 & 4.2 & 63 & 4.1 \\
Between 5 and 10\% & 1 & 0.0 & 41 & 2.7 & 41 & 2.7 \\
Between 10 and 20\% & 2 & 7.7 & 14 & 0.9 & 15 & 1.0 \\
Between 20 and 50\% & & & 6 & 0.4 & 8 & 0.5 \\
Total & 27 & 100.0 & 1,503 & 100.0 & 1,530 & 100.0 \\
\hline
\end{tabular}

per cent of the generated scenarios, the error ranged between + and -10 per cent.

Therefore, according to the results obtained, the separation of linear financial instruments into their risk factors significantly simplifies the quantity of information and the number of calculations necessary. The error caused by this simplification is within the proposed error margin, meaning that it should be an acceptable alternative for the definition of a set of information on linear instruments to be collected by the supervisor. 


\section{NONLINEAR FINANCIAL INSTRUMENTS}

Generally, for the nonlinear instruments, the management risk systems, RiskMetrics ${ }^{\mathrm{TM}}$, for example, uses greeks. The greeks are derivatives of the price of an option in relation to its risk factors, representing how the price of an option would react due to infinitesimal fluctuations on its risk factors. The estimated fluctuation of the price of a European call option using greeks is given by the following equation:

$$
\begin{aligned}
\mathrm{d} c \cong & \Delta \mathrm{d} S+\frac{1}{2} \Gamma(\mathrm{d} S)^{2}+v \mathrm{~d} \sigma+\rho_{i} \mathrm{~d} i \\
& +\rho_{q} \mathrm{~d} q+\Theta \mathrm{d} t
\end{aligned}
$$

where $\Delta$ is delta; $\Gamma$ is gamma; $v$ is vega; $\rho_{i}$ is rho of interest rate; $\rho_{q}$ is rho of dividend; $\theta$ is theta.

The following study aims at determining if the representation of the positions in options using greeks is strong enough for the supervisor. Collecting information on nonlinear instruments in this way enables the application of the stress test, which is considered to be adequate, and one can also obtain results within the limits indicated by the research.

In order to evaluate the significance of the error caused by the use of greeks and if it is acceptable, a European call option of foreign currency is used, with the following parameters: $S=3$; $c c=5$ per cent, $r=15$ per cent, $(T-t)=1$ year, $\sigma=10$ per cent, $X=3$. The price of this option in the beginning is 0.2942. The theoretical value of the option in each scenario $\alpha\left(c^{\alpha}\right)$ was calculated using the Black-Scholes equation, and the estimated value of the option through the use of greeks $\left(c_{G}^{\alpha}\right)$ is calculated by the following equation:

$$
\begin{aligned}
c_{G}^{\alpha} \cong & \Delta\left(S^{\alpha}-S^{0}\right)+\frac{1}{2} \Gamma\left(S^{\alpha}-S^{0}\right)^{2} \\
& +\Lambda\left(\sigma^{\alpha}-\sigma^{0}\right)+\rho_{i}\left(i^{\alpha}-i^{0}\right) \\
& +\rho_{c c}\left(c c^{\alpha}-c c^{0}\right)+c^{0}
\end{aligned}
$$

where 0 is the initial value of a parameter or price; $\alpha$ is the value of the parameter or price in the scenario $\alpha$.

The scenarios were the same scenarios applied to the linear instruments: spot value of foreign currency unit ranging between 1 and 5 Reais; interest rate free of risk, beginning at 15 per cent and ranging between 5 and 29 per cent, in intervals of 2 per cent; foreign exchange coupon ranging from 2 to 20 per cent, in intervals of 0.5 per cent. Scenarios for the volatility were also included (ranging from 5 to 50 per cent, in intervals of 5 per cent). Considering all the combinations among them, 39,780 scenarios were created.

The results of the simulation demonstrated that the error due to the comparison between the calculation performed, using greeks instead of the Black-Scholes equation, was within the + or -10 per cent margin, which would be considered acceptable according to the study, in only 14.1 per cent of the scenarios (Table 3).

It is important to notice that the results of this simulation can be extended to other options with other values of $S$ and $X$, as the proportion between the $S$ and $X$ of the simulated scenarios is kept.

The collection of information on nonlinear financial instruments using greeks produces highly unsatisfactory results, as the collected data do not enable the supervisor to have confidence that the obtained result really represents the effect that would occur in a financial institution. 
Table 3: Error generated by the use of greeks

\begin{tabular}{lrrrrrr}
\hline Gap bands & $\begin{array}{c}\text { Extreme } \\
\text { scenarios }\end{array}$ & \% vertical & Other scenarios & \% vertical & All scenarios & \% vertical \\
\hline Less than -50\% & 34 & 42.0 & 12,418 & 31.3 & 12,452 & 31.3 \\
Between -50 and -20\% & 4 & 4.9 & 7,231 & 18.2 & 7,235 & 18.2 \\
Between -20 and -10\% & - & 0.0 & 2,386 & 6.0 & 2,386 & 6.0 \\
Between -10 and -5\% & 1 & 1.2 & 1,305 & 3.3 & 1,306 & 3.3 \\
Between -5 and -2.5\% & - & 0.0 & 665 & 1.7 & 665 & 1.7 \\
Between -2.5 and 0\% & - & 0.0 & 757 & 1.9 & 757 & 1.9 \\
Between 0 and 2.5\% & 2 & 2.5 & 793 & 2.0 & 795 & 2.0 \\
Between 2.5 and 5\% & 2 & 2.5 & 841 & 2.1 & 843 & 2.1 \\
Between 5 and 10\% & 5 & 6.2 & 1,234 & 3.1 & 1,239 & 3.1 \\
Between 10 and 20\% & 5 & 6.2 & 1,406 & 3.5 & 1,411 & 3.5 \\
Between 20 and 50\% & 4 & 4.9 & 1,989 & 5.0 & 1,993 & 5.0 \\
More than 50\% & 24 & 29.6 & 8,674 & 21.8 & 8,698 & 21.9 \\
Total & 81 & 100.0 & 39,699 & 100.0 & 39,780 & 100.0 \\
\hline
\end{tabular}

One alternative to be explored for the collection of data on nonlinear financial instruments is transforming all the positions in options in European plain vanilla options. ${ }^{27}$

In order to adopt this alternative, it is necessary to verify theoretically the situations in which this alternative is applicable and the limitations that should be considered.

The options that are not European plain vanilla options can be divided into two groups: the American options (plain vanilla) and the exotic options. The American options are generally priced using binomial trees.

Nonetheless, literature on this subject shows ${ }^{28}$ that the American call options on shares, which do not pay dividends, should never be exercised before their expiry date, and, therefore, can be priced as European call options. One extension of this theory says that when dividends are paid before the expiry date on an American call option, the ideal choice is to only exercise it just before the last dividend payment. This led some theorists ${ }^{29}$ to suggest a pricing procedure that makes use of this characteristic. Basically, it is necessary to calculate the price for two European call options: one expiring along with the American option and the other expiring just before the payment of the last dividend. The price of an American option will be the greater of these two values. Yet according to the literature, the error generated using this method is 1.48 per cent. $^{28,30}$

The American options that do not pay dividends or pay discreet dividends at expected dates can be priced as if they were European options, having observed the rule contained in the last paragraph.

The American options that pay dividends continuously remain a pending solution. It would be the case of an option on foreign currency, for example. In this case, the foreign exchange coupon is considered as a dividend of 
the underlying asset. If it is demonstrated that the fluctuation of the price of an American option that pays dividends continuously in different scenarios is near to the fluctuation of a European option with the same scenarios, then it could be reported as a European option.

In order to evaluate this possibility, a study was conducted with eight American options with different expiry dates and with the same parameters: $S=3, c c=10$ per cent, $r=20$ per cent, $\sigma=30$ per cent, $X=3$. The theoretical prices of these options at the initial moment, using binomial trees and the Black-Scholes equation are shown in Table 4:

The extreme values of the applied scenarios are detailed in Table 5. Each one of them was, however, divided into smaller intervals as described in the other scenarios applied. All combinations among the scenarios resulted in 2,160 scenarios for each option.

According to the results of the simulations performed, the error caused by treating American options as European options is within the error margin accepted by the study $( \pm 10$ per cent) only for options with expiry date up to one year (Table 6).

Nevertheless, despite the results being shown to be acceptable only for the options up to one year, they are sufficient for accepting the presentation of American options as European options because the maturity structure of options traded in Brazil is extremely short, up to one year.

A short maturity structure is not an exclusive characteristic of the Brazilian market. According to Carvalho, ${ }^{31}$ for example, the longest American option traded in England has an expiry period of less than one year.

Yet, there remain the exotic options. An exotic option is one of the denominations given
Table 4: Theoretical prices of options at the initial moment

\begin{tabular}{lll}
\hline Maturity & American & European \\
\hline 1 month & 0.1151 & 0.1151 \\
2 months & 0.1685 & 0.1686 \\
3 months & 0.2112 & 0.2113 \\
6 months & 0.3111 & 0.3112 \\
1 year & 0.4543 & 0.4543 \\
1.5 year & 0.5595 & 0.5584 \\
2 years & 0.6415 & 0.6380 \\
2.5 years & 0.7077 & 0.6995 \\
\hline
\end{tabular}

Table 5: Extreme values of the applied scenarios

Scenarios

\begin{tabular}{llll}
\hline & Minimum & Initial & Maximum \\
\hline Dollar spot & 1.50 & 3.00 & 6.00 \\
Volatility & $5 \%$ & $30 \%$ & $100 \%$ \\
Foreign exchange & $5 \%$ & $10 \%$ & $20 \%$ \\
coupon & & & \\
Interest rates & $5 \%$ & $20 \%$ & $50 \%$ \\
\hline
\end{tabular}

to options that are not plain vanilla or standardised. In this category are included the over-the-counter options, developed for addressing the specific needs of each client, and the flexible options, traded in stock exchanges, with some standardised characteristics and other characteristics open to negotiation, such as the exercise price, the maturity period or the kinds of barriers.

There is an enormous diversity of exotic options, and frequently, new kinds of exotic options are created. The most known 
Table 6: Percentage distribution according to error bands

Percentage distribution according to error bands

\begin{tabular}{lllll}
\hline Expiring date & Equal (\%) & $\begin{array}{l}\text { Between } 100 \text { and } \\
110 \%(\%)\end{array}$ & $\begin{array}{l}\text { More than } \\
110 \%(\%)\end{array}$ & Total (\%) \\
\hline 1 month & 93.4 & 6.3 & 0.4 & 100.0 \\
2 months & 91.0 & 8.2 & 0.8 & 100.0 \\
3 months & 88.7 & 9.3 & 2.0 & 100.0 \\
6 months & 83.4 & 12.5 & 4.2 & 100.0 \\
1 year & 72.9 & 18.4 & 8.7 & 100.0 \\
1.5 year & 64.5 & 21.8 & 13.7 & 100.0 \\
2 years & 58.4 & 23.2 & 18.4 & 100.0 \\
2.5 years & 54.4 & 23.2 & 22.4 & 100.0 \\
Total & 75.8 & 15.3 & 8.8 & 100.0 \\
\hline
\end{tabular}

are: barrier options, dual strike options, lookback options, Asian options and compound options. $^{28,32}$

In most of the cases, there is no analytical solution for the evaluation of exotic options. For these options, the numerical procedures presented by Hull, ${ }^{28}$ mainly binomial trees and Monte Carlo simulation, are used.

Despite the difficulties in pricing, in some cases it is possible to find analytical solutions. It is the case, for example, of the exotic options with a simple barrier - in this kind of option, if the barrier is touched in the expiry data, the payoff is limited to the difference between the exercise price and the barrier price. It is possible to build a portfolio of European options that reproduce the cash flow of this exotic option. For example, a long position in a call option with a single barrier is equivalent to the buying of a plain vanilla call, with the same exercise price of the exotic option and the selling of a call option plain vanilla, when the exercise price is equal to the barrier.
An evolution of this idea, known as static reproduction of options, presented by Derman et al. ${ }^{33}$ basically consists in finding a portfolio of plain vanilla options whose value across a frontier is equivalent to the value of the exotic option in the same frontier, because that if two portfolios have the same value in the same frontier, they will have the same value in all points inside this frontier, ${ }^{28,34}$ therefore enabling the pricing or hedging of an exotic option.

One critique to this kind of methodology is that the options necessary to the replication are not always available in the market. This criticism is relevant if the methodology is being used to hedge one position, but, as the objective of this study is to calculate the 'theoretical value' of the option, this critic loses relevance.

Derman et al..$^{33}$ demonstrate an application of this methodology for a knock up-and-out option, but affirm that it can be extended to other kinds of options, such as, dual-strike-options, interest rate options, foreign currency options or options with more than one underlying asset. 
Other authors, more than only looking for means of replicating statically other types of options, searched for alternatives in order to solve some static replication problems: Carr et al. ${ }^{35}$ and Carr and $\mathrm{Chou}^{36}$ present an alternative approach to static replication and how to proceed with different types of exotic options. Liljefors ${ }^{37}$ proposes an alternative to static replication under dynamical market conditions using optimisation techniques. Sbuelz ${ }^{38}$ presents static replication for two barrier options. Ilhan and Sircar ${ }^{39}$ aimed at optimising the hedge of exotic options using a combination of static replication and dynamic replication. All those works, nevertheless, aimed at the same objective: finding a portfolio basically composed by plain vanilla options or 'simple' instruments that represent the same payoff of an exotic option.

Theoretically, this technique, when reducing an exotic option to a portfolio of plain vanilla European options, enables these options to be included in the proposed report.

Nonetheless, it is necessary to assess the quality of the obtained results with this technique.

Testing a knock up-and-out option - in this type of option if the underlying asset price rises above a pre-established value (barrier), the option expires - this methodology presents satisfactory results for fluctuations in the underlying asset; however, when all the parameters, such as interest rate and volatility fluctuate at the same time, the results do not meet the proposed quality standard.

The methodology proposed by Derman et al. ${ }^{33}$ is acceptable only for stress scenarios for the underlying asset. Although changes proposed by other authors have not been tested, considering that in the Brazilian market exotic options which require the use of this kind of methodology represents only 0.5 per cent of total derivatives listed on clearing houses, the use of this methodology does not bring big distortions to the results.

Positions in exotic options and in American options can be represented by plain vanilla European options, according to the methodologies described in this study and their limitations. Therefore, the report used for the collection of information on nonlinear financial instruments was designed using the methodology explained in the next section. ${ }^{40}$

\section{PROPOSED INFORMATION SET}

The following sections contain reports that reproduce the proposed information sets for linear and nonlinear instruments. The comments on the use of each one and the results of some tests are also presented.

\section{Report for linear instruments}

As previously established, this document is designed based on data generated on an intermediary stage of the management risk systems, where the market value of the linear financial instruments is totalled by risk factor and mapped on to a vertices structure.

The market value of each financial instrument and the identification of risk factors are made according to the same methodology used for foreign currency securities with credit risk.

The quantity of data to be processed decreases significantly if positions are totalled up according to their risk factors. For example, if an institution has only two positions of the same value and maturity, one long in a foreign currency security with credit risk $\mathrm{BBB}$ and the other short in dollar future, the final situation would be as follows (Table 7). 
Table 7: Calculation of the net position by risk factor

Risk factors

Foreign currency Security with

Dollar future

Net

credit risk

position

+Dollar spot

-Dollar spot

-Foreign exchange coupon

+Foreign exchange coupon

0

-Credit premium (BBB)

-Interest rate free

$-\$$

of risk

The risk factors 'spot dollar' and 'foreign exchange coupon' of the foreign currency security were offset by the risk factors of the dollar future, remaining only a short position in credit risk and a short position in risk-free interest rate.

Mapping in vertices can be made according to different methodologies. Nevertheless, an option was made for linear mapping, because it is more intuitive, easily implemented and because it reacts better to the other methodologies when there are extreme fluctuations in volatilities and correlations. $^{41,42}$

The report for the collection of information on linear financial instruments will have the following features as shown in Table 8 .

Finally, positions held in shares can be reported individually or be transformed into number equivalent to stock exchange indexes through the beta of the CAPM. The risk credit ratings must be standardised according to a scale defined by the supervisor in order to make all of them comparable, ${ }^{1,43}$ and the risk factors to be informed must also be chosen by the supervisor among the most relevant to the financial system.

\section{How to use this information}

The use of this information basically follows the same structure used by a security described by equation (8). The position of each vertex must be reevaluated according to the fluctuation of each risk factor in the $\alpha$ scenario. Therefore, the impact on the portfolio value due to the fluctuation in the various risk factors is given by:

$$
\Delta V_{C}=\sum_{F R=1}^{j} \sum_{\nu=1}^{n}\left(V_{F R, v}^{\alpha}-V_{F R, v}^{0}\right)
$$

where $\Delta V_{C}$ is the fluctuation in the portfolio value; $F R$ is each one of the existing risk factors, ranging from 1 to $j ; v$ are the vertices in number of days, ranging from 1 to $n ; V_{F R, v}^{\alpha}$ is the value of the risk factor $F R$ in the vertex $v$ when applied to the $\alpha$ scenario; $V_{F R, v}^{0}$ is the value of the risk factor $F R$ in the vertex $v$ at the initial moment.

If the risk factor is a spot price, therefore:

$$
V_{F R, 1}^{\alpha}=\frac{\left(F R_{1}^{\alpha}-F R_{1}^{0}\right)}{F R_{1}^{0}} \times V_{F R, 1}^{0}
$$

where $F R_{1}^{\alpha}$ is the value of the risk factor in the $\alpha$ scenario; $F R_{1}^{0}$ is the value of the risk factor in the initial scenario. 
Table 8: Example of report on positions in linear instruments

\begin{tabular}{|c|c|c|c|c|c|c|}
\hline \multirow[b]{2}{*}{ Risk factors } & \multicolumn{6}{|c|}{ Vertices (weekdays) } \\
\hline & 1 & 22 & 67 & 132 & 252 & 504 \\
\hline \multicolumn{7}{|l|}{ Interest rate free } \\
\hline \multicolumn{7}{|l|}{ of risk } \\
\hline \multicolumn{7}{|l|}{ Foreign exchange } \\
\hline \multicolumn{7}{|l|}{ rate } \\
\hline \multicolumn{7}{|l|}{ Spot dollar } \\
\hline \multicolumn{7}{|l|}{ Ibovespa } \\
\hline \multicolumn{7}{|l|}{ Credit risk AAA } \\
\hline \multicolumn{7}{|l|}{ Credit risk AA } \\
\hline \multicolumn{7}{|l|}{ Credit risk A } \\
\hline \multicolumn{7}{|l|}{ Credit risk $\mathrm{BBB}$} \\
\hline$\ldots$ & & & & & & \\
\hline
\end{tabular}

OBS: the grey lines are due to the fact that for spot prices there are information only for the vertex 1 day.

$$
V_{F R, v}^{\alpha}=\frac{\left(F R_{v}^{\alpha}-F R_{v}^{0}\right)}{\left(1-F R_{v}^{0}\right)} \times V_{F R, v}^{0}
$$

where $F R_{v}^{\alpha}$ is the aggregated rate for the vertex $v$ in the $\alpha$ scenario; $F R_{v}^{0}$ is the aggregated rate for the vertex $v$ in the initial scenario.

\section{Evaluation of the results obtained with this information}

In order to evaluate if the results obtained using only information of the proposed document meets the defined criteria, that is, error not bigger than \pm 10 per cent, two portfolios were tested. The first portfolio represents all the linear financial instruments, assets or liabilities existing in the Brazilian financial system $-\mathrm{BFS}^{44}$ in September 2003 and the second portfolio represents all the futures listed on the Stock and Futures Exchange - BM\&F in 23rd January, 2004.

The portfolio held by the BFS in September 2003 was as follows (Table 9).
In the process of building the report that presents the risk factors mapped on to vertices, the values classified as cash, fixed assets and demand deposits are not directly influenced by market risk fluctuations or credit risk, and therefore they are not included. The net equity is indirectly influenced by the reevaluation of the various positions; therefore, it would not be included in the map either. The final report on risk factors mapped on to vertices of the BFS is as follows (Table 10).

The scenarios to be applied are based on major fluctuations of the following risk factors: spot dollar, Selic interest rate, Bovespa Index and the yield curve in the last ten years in the Brazilian market. For the dollar coupon, the major fluctuations in the last five years are considered, and for credit risk the downgrade of two levels is considered. ${ }^{1,45}$ Four hundred and eighty-six scenarios were built, representing all the possible combinations among the 
Table 9: Balance sheet - All the BFS (as of September 2003)

\begin{tabular}{lrllr}
\hline Assets & \multicolumn{3}{c}{ Liabilities } \\
\hline Cash & 22,790 & Deposits & Interbank & 277,109 \\
Interbank deposits & 154,692 & & Time & 240,903 \\
Federal Government securities & 293,999 & & Demand & 60,993 \\
Shares & 4,899 & & Savings & 139,973 \\
Loans & 433,822 & Loans & In Brazil & 79,594 \\
Nonclassified accounts & 60,762 & & Abroad & 95,872 \\
Fixed assets & 49,416 & Net Equity & & 125,937 \\
& & & & $1,020,380$ \\
Total assets & $1,020,380$ & Total Liabilities & &
\end{tabular}

Source: Central Bank of Brazil's website - Quarterly financial information.

following values for each risk factor

(Table 11).

The results obtained show that, for the adopted portfolio, only in nine scenarios the error would rise above the limit accepted by the study. And, even in those cases, the error would not reach -15 per cent, demonstrating that the map for the linear instruments, considering the example, would present satisfactory results (Table 12).

The portfolio of all the future contracts listed on BM\&F, including dollar futures, dollar coupon futures and interbank deposits (DI) futures on 23rd January, 2004, presented the structure as shown in Table 13.

This portfolio can be divided into three risk factors: dollar spot, dollar coupon and fixed interest rates. Applying the same scenarios described in the previous example, 27 scenarios were built using the major positive and negative fluctuations verified in the last few years. Two errors were calculated: in relation to the daily settlement and in relation to the future value of the portfolio.
In four of the 27 scenarios, the adjustment error would be higher than the error margin considered acceptable by the study. The future value error would, however, never be significant. The major adjustment error (74.9 per cent) is due to the fact that the fluctuation of the future value, used as basis for the adjustment calculation, is very small. In these cases, a small difference between the theoretical fluctuation and the projected fluctuation can result in a significant percentage difference among the adjustments, despite the fact that the future values are very close. In the other cases, in spite of the fact that the adjustment error is higher than that accepted by the study, it was never higher than 20 per cent.

In other words, the proposed report on linear instruments grouped by risk factors and vertices presented a satisfactory performance even in extreme scenarios, as verified by the scenarios in Brazil in the last few years, both for the portfolio that represents the BFS and for the portfolio that represents all the futures listed on $\mathrm{BM} \& \mathrm{~F}$. 
Table 10: Report on positions in linear instruments for BFS (September 2003)

\begin{tabular}{|c|c|c|c|c|c|c|c|c|c|c|c|c|c|c|}
\hline \multirow[t]{2}{*}{ Risk factors } & \multicolumn{14}{|c|}{ Vertices (weekdays) } \\
\hline & 1 & 22 & 67 & 132 & 252 & 504 & 756 & 1008 & 1260 & 1764 & 2268 & 2520 & 3780 & 5040 \\
\hline Spot dollar & 55,792 & - & - & - & - & - & - & - & - & - & - & - & - & - \\
\hline Dollar coupon & - & $(1,011)$ & (253) & $(7,762)$ & $(2,147)$ & $32,274)$ & - & $(11,167)$ & - & - & - & (620) & - & (559) \\
\hline Selic interest rate & $(122,417)$ & $(72,425)$ & $(18,106)$ & 56,191 & 15,542 & 83,821 & - & 28,252 & - & - & - & 9,877 & - & 1,146 \\
\hline Fixed interest rate & - & 41,855 & 10,464 & $(10,084)$ & $(2,789)$ & 6,545 & - & $(7,916)$ & - & - & - & $(2,307)$ & - & (136) \\
\hline Shares & 4,899 & - & - & - & - & - & - & - & - & - & - & - & - & - \\
\hline Credit risk AAA & - & $(31,554)$ & $(7,888)$ & $(23,921)$ & $(6,616)$ & $(21,142)$ & - & $(7,095)$ & - & - & - & $(5,636)$ & - & $(1,817)$ \\
\hline Credit risk AA & - & $(36,549)$ & $(9,137)$ & $(27,707)$ & $(7,664)$ & $(24,484)$ & - & $(8,210)$ & - & - & - & $(6,535)$ & - & $(2,103)$ \\
\hline Credit risk A & - & $(19,115)$ & $(4,779)$ & $(14,490)$ & $(4,008)$ & $(12,794)$ & - & $(4,288)$ & - & - & - & $(3,389)$ & - & $(1,084)$ \\
\hline Credit risk BBB & - & $(10,265)$ & $(2,566)$ & $(7,782)$ & $(2,152)$ & $(6,860)$ & - & $(2,287)$ & - & - & - & $(1,782)$ & - & (572) \\
\hline Credit risk BB & - & $(4,823)$ & $(1,206)$ & $(3,657)$ & $(1,011)$ & $(3,153)$ & - & $(1,003)$ & - & - & - & $(726)$ & - & (228) \\
\hline Credit risk B & - & $(2,838)$ & (710) & $(2,152)$ & $(595)$ & $(1,785)$ & - & (543) & - & - & - & (385) & - & (121) \\
\hline Credit risk CCC & - & $(4,822)$ & $(1,205)$ & $(3,655)$ & $(1,011)$ & $(2,943)$ & - & (867) & - & - & - & (598) & - & (193) \\
\hline
\end{tabular}


Table 11: Scenarios used in the assessment of the BFS's portfolio

\begin{tabular}{|c|c|c|c|c|c|c|c|c|c|c|}
\hline & \multirow{2}{*}{$\begin{array}{l}\text { Spot } \\
\text { dollar }\end{array}$} & \multirow{2}{*}{$\begin{array}{l}\text { Selic } \\
\text { rate }(\%)\end{array}$} & \multirow{2}{*}{$\begin{array}{l}\text { Ibovespa } \\
\text { index }\end{array}$} & \multicolumn{3}{|c|}{ Fixed interest rate (\%) } & \multicolumn{3}{|c|}{ Dollar coupon (\%) } & \multirow[t]{2}{*}{ Credit risk } \\
\hline & & & & 6 months & 12 months & 24 months & 6 months & 12 months & 24 months & \\
\hline High & 4.80 & 48.6 & 28,411 & 38.0 & 35.0 & 31.2 & 7.1 & 8.5 & 10.7 & $\mathrm{~N} / \mathrm{A}$ \\
\hline Low & 2.33 & 6.6 & 8,659 & 10.7 & 10.3 & 11.0 & 0.7 & 1.4 & 2.4 & 2 \\
\hline Initial & 2.92 & 19.8 & 16,010 & 18.2 & 18.1 & 18.6 & 2.0 & 3.1 & 5.1 & 0 \\
\hline
\end{tabular}

Table 12: Error in the estimation of the fluctuation of the BFS's portfolio

\begin{tabular}{lcr}
\hline Error band & Quantity & $\%$ \\
\hline Between -15 and $-10 \%$ & 9 & 1.9 \\
Between -10 and $-5 \%$ & 69 & 14.2 \\
Between -5 and $0 \%$ & 336 & 69.1 \\
Between 0 and 5\% & 72 & 14.8 \\
& & \\
Total & 486 & 100.0 \\
\hline
\end{tabular}

\section{Report for nonlinear instruments}

According to the discussion presented initially, the document to be evaluated for nonlinear financial instruments will be based on the hypothesis that all options can be summarised in the European options portfolio. In case of financial instruments with embedded options, the instruments were separated into two positions: one in a linear instrument and other in a nonlinear instrument. Each one was reported in the respective report.

After the exotic options have been transformed into plain vanilla options portfolios and the American options have been converted into European options, according to the presented methodologies, all the plain vanilla
European options can be grouped according to their underlying assets.

For each plain vanilla European option, call or put, with a different underlying asset, a report will be filled out. For this purpose, it is necessary to know the quantity - in underlying asset units, which generally is represented by the notional, multiplied by the number of options - the exercising price and the expiry date. Moreover, the percentage distance $(D \%)$ between the asset price and the exercise price must be calculated for each one of them:

$$
D \%{ }_{i}=\frac{\left(X_{i}-S\right)}{S}
$$

With all this information, the quantities are linearly mapped on to the report, first according to the expiry date and then according to the percentage distance between the exercise price and the spot price. Therefore, each option will be distributed into four cells of the report, and in each cell the quantities are included. They are reported as shown in Table 14.

\section{How to use this information}

In order to use the nonlinear instruments' report, the first stage is to price the report. For this purpose, the Black-Scholes equation is used. Each cell presents the price of an option, calculated for one underlying asset unit, 
Table 13: Summary of the futures contracts by type and expiring date

\begin{tabular}{|c|c|c|c|c|c|}
\hline \multirow[t]{2}{*}{ Expiring dates } & \multicolumn{3}{|c|}{ Types of future contracts } & \multirow[t]{2}{*}{ Total } & \multirow[t]{2}{*}{$\%$} \\
\hline & Dollar coupon & Interbank deposits & Dollar & & \\
\hline Up to 3 months & $49,091,898$ & $82,719,477$ & $21,785,149$ & $153,596,524$ & 45.8 \\
\hline 3 to 6 months & $19,604,679$ & $49,484,570$ & 935,672 & $70,024,920$ & 20.9 \\
\hline 6 to 12 months & $19,796,048$ & $44,890,745$ & $1,579,926$ & $66,266,718$ & 19.8 \\
\hline 1 to 1.5 year & $8,600,603$ & $7,038,126$ & 0 & $15,638,729$ & 4.7 \\
\hline 1.5 to 2 years & $5,279,583$ & $4,950,392$ & 0 & $10,229,975$ & 3.1 \\
\hline Above 2 years & $15,960,610$ & $3,655,955$ & 0 & $19,616,565$ & 5.8 \\
\hline Total & $118,333,420$ & $192,739,265$ & $24,300,747$ & $335,373,432$ & 100.0 \\
\hline
\end{tabular}

Table 14: Example of the positions map on non-linear instruments - Call European options

\begin{tabular}{|c|c|c|c|c|c|c|c|}
\hline \multirow[b]{2}{*}{ Maturity vertices } & \multicolumn{7}{|c|}{ Distance between $S$ and $X$} \\
\hline & $-15 \%$ & $-10 \%$ & $-5 \%$ & $0 \%$ & $5 \%$ & $10 \%$ & $15 \%$ \\
\hline \multicolumn{8}{|l|}{1} \\
\hline \multicolumn{8}{|l|}{10} \\
\hline \multicolumn{8}{|l|}{21} \\
\hline \multicolumn{8}{|l|}{35} \\
\hline \multicolumn{8}{|l|}{50} \\
\hline \multicolumn{8}{|l|}{70} \\
\hline$\ldots$ & & & & & & & \\
\hline
\end{tabular}

considering the period until the maturity and the percentage distance $(D \%)$ between the price of the underlying asset and the exercise price converted again into exercise price. Other required parameters - spot price, volatility and dividends - are collected by the supervisor in the market.

Therefore, the report price is:

$$
V C_{N L}=\sum_{p ; d=1}^{n} c_{(p x d)} Q_{(p x d)}
$$

where $V C_{N L}$ is the value of the nonlinear portfolio; $c_{(p x d)}$ is the price of an option for each cell $(p x d)$, result of the intersection of the period until maturity $(p)$ with the percentage distance between the underlying asset price and the exercise price $(d) ; Q_{(p x d)}$ is the quantity allocated in the report for the cell $(p x d)$.

In order to assess the impact of an $\alpha$ scenario on a portfolio, new parameters $f\left(S^{\alpha} ; \sigma^{\alpha} ; r^{\alpha} ; q^{\alpha}\right)$ must be established and it is necessary to recalculate the Black-Scholes equation to obtain the price of an option on the new scenario. This value must be multiplied by the respective quantity to obtain the value of the report on the 
new scenario $\left(V C_{N L}^{\alpha}\right)$ :

$$
V C_{N L}^{\alpha}=\sum_{p ; d=1}^{n} c_{(p x d)}^{\alpha} Q_{(p x d)}
$$

Therefore, the impact of the use of the new scenario is given by the following equation:

$$
\Delta V C_{N L}=V C_{N L}^{\alpha}-V C_{N L}^{0}
$$

where $V C_{N L}^{\alpha}$ is the value of the portfolio considering the $\alpha$ scenario, $V C_{N L}^{0}$ is the value of the portfolio at the initial time.

\section{Evaluation of the results obtained with this information}

In order to assess if the results obtained using only the information contained in the proposed report meet the requirement of error less or equal to \pm 10 per cent in relation to the results obtained by the full valuation method, two tests were performed: one using some options strategies, in order to verify if the risk inherent to each option is properly captured by the proposed document and the other assessing the foreign exchange options portfolio listed on the BM\&F on 23rd January, 2004.

The tests were performed using three kinds of strategies: box, butterfly and spread. For each strategy, the biggest fluctuations verified in the last few years in the Brazilian markets were used. In all the tests performed, the comparison between the value of the options portfolio in each strategy priced, using the Black-Scholes equation and the value of the portfolio obtained using the proposed report, was not higher than + or -2 per cent.

The BM\&F portfolio on 23rd January, $2004^{46}$ comprehended 100 call options and 15 put options, all European plain vanilla. The target was to verify if the estimated fluctuation in different stress scenarios, based on the report, would be close enough to the fluctuation of the portfolio value when the value of each option was recalculated individually using the BlackScholes equation (Table 15).

Table 15: Summary of the dollar options portfolio listed on BM\&F

\begin{tabular}{lllcc}
\hline As of 23rd January 2004 & & & Quantity \\
\hline Exercise prices bands & & Maturity bands & \\
\cline { 2 - 4 } & & Up to 3 months & 5 & Total 12 months \\
\hline From 2.7 to 3.05 & Call & 15 & 2 & 20 \\
& Put & 13 & 15 & 15 \\
From 3.05 to 3.4 & Call & 15 & 14 & 30 \\
From 3.40 to 3.75 & Call & 12 & 7 & 14 \\
From 3.75 to 4.05 & Call & 7 & 9 & 10 \\
From 4.05 to 4.40 & Call & 1 & 52 & 115 \\
Total & & 63 & & \\
\hline
\end{tabular}

Source: BM\&F website. 
The scenarios representing the major fluctuations verified in the last few years, in the Brazilian market for each risk factor, were applied to the portfolio and to the information contained in the proposed report. Eighty-one scenario results were evaluated, and in none of them was the error higher than that accepted by the study. Therefore, for this portfolio, the results are considered satisfactory (Table 16).

Therefore, the proposed document for the collection of information on nonlinear financial instruments adequately captured the risks inherent to the options strategies and the risks of the options portfolio listed on the BM\&F, even in extreme scenarios, as occurred in Brazil in the last few years.

\section{CONCLUSIONS}

Considering the increasing use of derivatives by financial institutions, to the point that they became one of the major revenue sources, this fact has brought to light the difficulties in the assessment of risk in financial institutions, once the effects of the derivatives on the institution are not transparent to supervisors and to market analysts. Taking into consideration the need of the banking supervisor, in the monitoring financial system activity, is to have comparable risk measures in order to distinguish between institutions or assess which institutions, given a scenario, could present problems. Hence, an instrument for the collection of information on risks incurred by financial institutions, which enabled supervisors to perform this task, was evaluated.

Analysing the information and reports to be collected, the study aimed at choosing, within the risk management systems, which data would
Table 16: Error comparing the estimated value and the theoretical value

\begin{tabular}{lc}
\hline Error bands & Quantity \\
\hline From -5 to $0 \%$ & 16 \\
From 0 to $5 \%$ & 64 \\
From 5 to $10 \%$ & 1 \\
Total & 81 \\
\hline
\end{tabular}

be necessary and how they are usually treated, with the purpose of not imposing new costs on the financial institutions.

For the linear financial instruments, the separation into risk factors and the aggregation in maturity vertices showed themselves to be a consistent alternative, capable of presenting satisfactory results even in major price and other market fluctuations parameter scenarios.

For the nonlinear financial instruments, the use of greeks has been shown to be not adequate when extreme fluctuation scenarios were applied. This is due to the fact that they represent only the effect of infinitesimal fluctuations of each risk factor in the price of a financial instrument and not fluctuations in stress situations.

As an alternative, the possibility of representing all kinds of existing options by European options or European options portfolios, without producing a significant error, was assessed. For most options, alternatives meeting this hypothesis were found in literature. But, in both cases, this proposal presented some limitations.

American options can be represented by a European option when it does not pay dividends or pays discreet dividends at expected dates. Nevertheless, when representing American 
options with continuous dividends by a

European option, the results were satisfactory only for those with maturity date of less than one year. But, according to stock exchange and clearing houses' data, the derivatives market in Brazil, mainly the options market, presents maturity dates of less than one year, therefore enabling the use of this simplification. This statement is also valid for other countries, such as England.

It is also important to have in mind that, in these tests, we used scenarios more severe than those that happened in the last ten years in Brazil, and in the Russian, Asian, Brazilian and Argentina crises. If the country where this model will be applied has a smaller historical variation when compared to Brazil, it will be possible to use the above simplification for longer maturity options.

In the case of exotic options, the exotic option with simple barrier can be represented by a European plain vanilla options portfolio. In the other cases, the results were satisfactory only when there was a fluctuation in the underlying asset price. This is due to the characteristics of the methodology chosen for transforming exotic options in European plain vanilla options portfolios. This problem is minimised by the fact that this methodology would be applicable to only 0.5 per cent of the financial volume of derivatives in Brazil. Moreover, this paper mentions methodological alternatives that could be tested.

In all tests performed, reports for both linear and nonlinear financial instruments presented results within the error margin, established as acceptable, as compared to the calculations performed according to the full valuation method. Furthermore, the report for nonlinear financial instruments showed them to be capable of capturing the risk of various strategy options.

In this work, the collection of information on market risk and credit risk was assessed. Nevertheless, there are other risks such as liquidity risk, that should be considered. An alternative would be to include in each risk factor the information of the underlying asset liquidity (high, medium and low, for example).

The proposed documents do not involve the adoption of sophisticated systems by the supervisory authorities and, at the same time, enable the measurement of the same risk for all financial institutions, using the same methodology, or the application of the same stress scenario, making results comparable with an acceptable accuracy level.

It must be made clear that it is not up to the supervisor to manage the risks of the supervised banks, but simply to know the risk profile of each institution and to monitor the risk volume each one is incurring in relation to its capital, for example. Therefore, the proposed system should accept an error margin where the results enable knowing the institution, despite the fact that they are not precise.

Finally, in this paper, the focus was on bank supervision, but this approach could be useful for others, such as risk managers, financial institutions or academicians. This approach can be helpful in building risk management models as it can be used as an input in such models.

\section{Acknowledgments}

The opinions expressed in this paper are those of the authors and do not necessarily reflect those of the Central Bank of Brazil. Benjamin M. Tabak gratefully acknowledges financial support from CNPQ Foundation. 


\section{References and Notes}

1 Crouhy, M., Mark, R. and Galai, D. (2001) 'Risk Management', McGraw-Hill, New York.

2 Lopes, A.B. and Lima, I.S. (1998) 'Disclosure de Operações com Derivativos: Panorama Internacional', Caderno de Estudos, São Paulo, FIPECAFI, v. 10, n. 18 , mai./ago.

3 The Statement $133^{4}$ with the changes of the Statement $137,{ }^{5} 138^{6}$ and $149^{7}$.

4 FASB (1998) Statement No. 133: Accounting for Derivative Instruments and Hedging Activities, June.

5 FASB (1999) Statement No. 137: Accounting for Derivative Instruments and Hedging Activities Deferral of the Effective Date of FASB Statement No. 133 - an amendment of FASB Statement No. 133, June.

6 FASB (2000) Statement No. 138: Accounting for Certain Derivative Instruments and Certain Hedging Activities-an amendment of FASB Statement No. 133, June.

7 FASB (2003) Statement No. 149: Amendment of Statement 133 on Derivative Instruments and Hedging Activities, April.

8 In the Basel Capital Accord and in the text jointly written with the IOSCO. See bibliography: BIS ${ }^{9}$ Amendment to the Capital. Accord to Incorporate Market Risks and BIS. ${ }^{10,11}$ The New Basel Capital Accord.

9 BIS (1996) 'Amendment to the Capital Accord to Incorporate Market Risks', Basel Committee on Banking Supervision, January.

10 BIS - BANK FOR INTERNATIONAL SETTLEMENTS (2003a) 'Public Disclosures by Banks: Results of the 2001-Disclosure Survey', Basel Committee on Banking Supervision, May.

11 BIS (2003b) 'The New Basel Capital Accord Consultive Document', Basel Committee on Banking Supervision, July.

121999 publication, entitled 'Public Disclosure of Trading and Derivatives Activities'.

$13(\ldots)$ assess if the bank is viable, meets its regulatory requirements, and is sound and capable of fulfilling financial commitments to its creditors (including depositors). Supervisory authorities also verify whether or not the bank's operations are likely to jeopardise the safety of the banking system as a whole' (Greuning and Bratanovic, ${ }^{14}$ p. 16).

14 Greuning, H.V. and Bratanovic, S.B. (1999) 'Analyzing Banking Risk', The World Bank, Washington, DC.

15 The Federal Reserve System (FED), from the United States of America, the Financial Services Authority (FSA), from the United Kingdom, the Deutsche Bundesbank, from German, the Commission de
Surveillance du Secteur Financier (CSSF), from Luxembourg and the Central Bank of Brazil (Bacen), from Brazil.

16 BIS, ${ }^{17,18}$ p. 8.

17 BIS (1999a) 'Recommendations for Public Disclosure of Trading and Derivatives Activities', Basel Committee on Banking Supervision, May.

18 BIS (1999b) Trading and Derivatives Disclosures of Banks and Securities Firms - Results of the survey of public disclosures in 1998 annual reports. Basel Committee on Banking Supervision, December.

19 See, as example, Hull, J. (2000) 'Futuros, Opções e Outros Derivativos’, BM \& F, São Paulo, p. 363 Jorion $^{20}$, p. 182.

20 Jorion, P. (1999) 'Value at Risk: A nova Fonte de Referência para o Controle do Risco de Mercado', Cultura, São Paulo.

21 RiskMetrics, M (1996)', Technical Document, 4th edn., December.

22 JP Morgan (1996) 'RiskMetrics', Technical Document, New York, p. 123.

23 Rating used by Standard \& Poor's, like Table 1.

24 It is possible to find in books $i_{c}=r+r c$. If $\left(1+i_{c}^{\star}\right)=(1+r)(1+r c) \therefore i_{c}^{\star}=r+r c+r \times r c$ and supposing $r<1, r<1$ and both being small enough, then $r \times r$ can be considered next to zero, then $i_{c}^{\star} \cong i_{c}$.

25 Other examples of risk factors separations can be find at JP Morgan (1999) 'RiskMetrics', Technical Document. New York.

26 This relation is obtained as follows: calculating the expected value at loan's maturity $(E(V F))$, using the default probability, the security will have two likely results: it will not be paid (probability of default $p$ ) or it will be paid (probability of default $(1-p)$ ). In practice, it will be assumed zero return of the loan in case of default. Therefore,

$$
E(V F)=p \times 0+(1-p) \times V F=(1-p) \times V F
$$

According to the nonarbitrary hypothesis, a financial instrument with credit risk must have return equivalent to a financial instrument without credit risk of future value equal to $E(V F)$, that is, the present value of both instruments should be equal. Therefore,

$\frac{V F}{\left(1+i_{c}\right)}=V P=\frac{E(V F)}{1+r}$ replacing equations and using the definition of $\left(1+i_{c}\right)=(1+r)(1+r)$, after simplifying the equation: $\frac{V F}{(1+r)(1+r c)}=\frac{(1-p) \times V F}{(1+r)}$ and, finally, $(1+r c)=\frac{1}{(1-p)}$

27 The authors thank Professor Theodore Barnhill, from the George Washington University, for suggesting this approach.

28 Hull, J. (2001) 'Opções, Futuros e Outros Derivativos', 3rd edn. BM\&F, São Paulo.

29 Black, F. (1976) 'The Pricing of Commodity Contracts', Journal of Financial Economics, Vol.3, No. 1-2, pp.167-179. 
$30 \mathrm{Hull}^{28}$ presents a study made by Whaley, R.E. (1982) 'Valuation of American Call Options on DividendPaying Stocks: Empirical Tests', Journal of Financial Economics, Vol. 10, March, pp. 29-58.

31 Carvalho, A.P. (2003) 'Pricing American Options', Dissertation, Lancaster University.

32 See Hull, $^{28}$ (pp. 536-538).

33 Derman, E., Ergener, D. and Kani, I. (1994) 'Static Options Replication', Quantitative Strategies Research Notes, Goldman Sachs, May.

34 (Hull, ${ }^{28}$ pp. $536-538$ ).

35 Carr, P., Ellis, K. and Gupta, V. (1998) 'Static Hedging of Exotic Options', Journal of Finance', Vol. 53, pp. 1165-1190.

36 Carr, P. and Chou, A. (1997) 'Hedging Complex Barrier Options', April.

37 Liljefors, J. (2001) 'Static Hedging of Barrier Options Under Dynamic Market Conditions', September.

38 Sbuelz, A. (2000) 'Hedging Double Barriers With Singles', November.

39 Ilhan, A. and Sircar, R. (2003) 'Optimal StaticDynamic Hedges for Barrier Options', November.

40 We thank Professor Theodore Barnhill for suggesting this approach.
41 Mina, ${ }^{42}$ p. 12: 'We propose a linear cash flow map that performs well even under extreme volatility and correlation scenarios. Moreover, under normal circumstances, the results produced by the proposed map and the RiskMetrics maps are virtually indistinguishable. In addition, the linear map is very intuitive and easy to implement'.

42 Mina, J. (1999) 'Improved Cashflow Map', RiskMetrics Group: New York.

43 See example at Crouhy et al. ${ }^{1}$ (p. 272).

44 There is no detailed information available comprehending all the BFS, therefore, some simplifications were necessary. However, the original characteristics were preserved to the possible extent.

45 The two levels downgrade is the methodology used by the Central Bank of Brazil on its Financial Stability Report, available at the website 〈http:www.bcb.gov.br〉 and is also used by Crouhy et al. ${ }^{1}$ as a methodology for the credit risk sensitivity analysis.

46 Excludes those maturing on February 2004, because information on expired options is not available at the $\mathrm{BM} \& \mathrm{~F}$ website. 